\title{
Juan José Apolinaire Pennini
}

En la mañana del 8 de agosto de 2009 recibimos la triste y dolorosa noticia de la muerte en Santa Fe, Argentina, del notable epidemiólogo y amigo, profesor Dr. Juan José Apolinaire Pennini. Se encontraba en esos momentos en su patria original, brindando sus conocimientos y experiencia en la Universidad de La Plata, cumplimentando una invitación de esa institución académica. En 49 años solo había viajado en dos ocasiones a ese país, en 1963 y 1995, por cortos períodos de tiempo y por razones familiares.

El profesor Apolinaire nació en la República Argentina el 5 de febrero de 1933. Se graduó de médico en Buenos Aires, en 1960. Inició su vida laboral en un pequeño hospital rural en la Provincia de Salta.

En 1962 decidió colaborar con la Revolución triunfante en Cuba y arribó a La Habana el 28 de enero de ese año para, desde entonces -al igual que el heroico Comandante Guerrillero- echar su suerte con nuestro pueblo.

A su llegada a Cuba, fue ubicado en el Hospital de Gibara, Oriente, como pediatra. Promotor incansable de la salud durante los primeros años de la Revolución participó como médico asistencial, higienista, director de hospitales y director regional, organizador y responsable de todas las tareas y programas de salud en la zona de Oriente Norte, incluyendo la erradicación del paludismo, la difteria, el tétanos neonatal y la poliomielitis, entre otras enfermedades comunes en esa época. Se incorporó temprano a las Milicias Nacionales Revolucionarias, al sindicato, a los CDR y fue fundador de la Defensa Civil.

En 1967 fue enviado a superarse al extranjero y se graduó, entre los 5 primeros expedientes, como máster en el curso de Administración de Salud en la Escuela de Salud Pública de Chile. Al regresar de Chile es designado Epidemiólogo Provincial primero y Subdirector Provincial de Higiene y Epidemiología después, en la Provincia de Oriente Norte con sede en la ciudad de Holguín.

En 1970 se trasladó a la Provincia de Las Villas, como Subdirector Regional al inicio y nombrado posteriormente Epidemiólogo Provincial, con residencia en Santa Clara.

En 1976 con motivo de la división político-administrativa pasó a trabajar a la nueva provincia de Cienfuegos como epidemiólogo primero y como Subdirector Provincial de Higiene y Epidemiología, durante otros 15 años, de los 33 muy fructíferos que compartió entre nosotros en Cienfuegos.

Sencillo, humano, altruista, lo vimos ir y venir con su andar lento, pero seguro, entregarse a la labor administrativa, técnica y científica, lo mismo en una oficina, que en un laboratorio, que en las calles donde, según solía decir muy sabiamente, es donde se hace la Epidemiología. No solo antes en Oriente, como luego en Santa Clara y Cienfuegos, sino en todo el país, supo dejar una estela de amor y reconocimiento a su talento, el cual no lo utilizó jamás para beneficio personal, sino que le hizo honor a su especialidad, a la cual entregó su vida y la puso siempre al servicio de la colectividad. 
En pos de la Higiene y la Epidemiología transmitió a más de tres generaciones la necesidad de conocerla, estudiarla y aplicarla, con el rigor que él le imponía tanto en el desempeño de la administración, como en la docencia o la investigación, pues en todos estos ámbitos se dedicó con esmero. Alcanzó el primer grado en la especialidad de Salud Pública y el segundo grado en la especialidad de Epidemiología.

Fue miembro de la junta de gobierno de la Sociedad Cubana de Higiene y Epidemiología y, por muchos años, presidente del Capitulo de la Sociedad en la provincia. También fue miembro del Grupo Nacional de Epidemiología y participó a nivel nacional en la elaboración de los programas de lucha contra la sífilis, lepra, gonorrea, leptospirosis, rabia animal, infecciones respiratorias agudas, enfermedad meningocóccica y fiebre tifoidea.

Dejó su impronta como jefe del grupo técnico de la defensa civil en el territorio durante la epidemia del dengue hemorrágico en 1981. Cumplió misión internacionalista en la República Popular de Angola de 1982 a 1984, como Asesor del MINSAP y Epidemiólogo Asesor de la misión militar cubana, especialmente dedicado a la ardua tarea de disminuir el riesgo de la introducción de paludismo en Cuba. Se desempeñó como miembro del consejo asesor durante la epidemia de neuropatía en los años 90 del pasado siglo. Esa gran capacidad de trabajo la puso de manifiesto al contribuir directamente en la formación de todos los especialistas del ramo en las tres provincias centrales e incluso en otras regiones del país, pues además de profesor fue el presidente de tribunales nacionales, territoriales y provinciales para la promoción y graduación de todos los especialistas que en las últimas tres décadas se formaron en el territorio.

Representó a Cuba en diversos eventos, entre los que se destacan:

- Chile (1967), curso de 10 meses, en la Escuela de Salud Pública de la Universidad de Chile.

- República Democrática Alemana (1976), donde participó en el Simposio de países del CAME para vacunas antivirales y en un curso por tres meses en el Instituto de control de infecciones de Berlín, y allí formaliza la compra, a nombre del MINSAP, de la vacuna antisarampionosa en ámpulas de dos dosis para Cuba.

- Washington, Estados Unidos de Norte América (1982), donde realizó una estancia de mes y medio, como asesor temporero de la OPS del grupo de expertos en "enfermedades de transmisión sexual."

Como consultante incansable, no escatimó horas de su sueño para tutelar y asesorar, hasta el último momento, decenas y decenas de trabajos científicos de residentes, especialistas, másteres e incluso doctores.

Como docente, alcanzó la categoría de Profesor Auxiliar, con más de 40 años de experiencia en Higiene y Epidemiología y Profesor Consultante hace más de una década.

Publicó 46 artículos en revistas científicas cubanas, españolas y de la OMS y participó en el Congreso virtual de Cardiología de Argentina.

Todos estos resultados lo hicieron acreedor de títulos honoríficos y múltiples reconocimientos, entre ellos, los de Profesor de Mérito, Medalla 50 Aniversario del Ministerio de Salud Pública de Cuba y Fundador del Hospital Lenin en 1965, de la 
docencia Médica Superior en Villa Clara en 1971 y de la Facultad de Ciencias Médicas de Cienfuegos en 1979, así como la distinción por la Educación Cubana.

Presidente vitalicio del Jurado del Premio Anual de la Salud en Cienfuegos, tutor, asesor o acompañante de multitud de trabajos de investigación, con preferencia por las tesis de especialización, investigador infatigable, escritor de "letra con filo", será difícil acostumbrarse a su ausencia. Su intensa y fructífera labor como epidemiólogo, salubrista, investigador y maestro, ha influido directa o indirectamente en prácticamente todos los profesionales de la salud del territorio y su inteligencia y sus enseñanzas han estado detrás de muchos de los resultados de la salud pública en la provincia de Cienfuegos en las últimas tres décadas. Su posición vertical como revolucionario, su amor por Cuba, su ejemplo como padre, esposo, amigo, consejero, han sido constantes que hemos disfrutado cotidianamente, casi de manera imperceptible.

Su entrega personal a estas actividades no le impidió atender a su familia, a sus amigos. Como comunista consagrado, alcanzó la militancia después de haber obtenido la ciudadanía cubana, única condición que no cumplía para formar parte anteriormente de las filas del Partido, lo cual deseaba con vehemencia.

Se nos fue Apo o Apolo, como a sus amigos les gustaba decirle, pero sólo físicamente, su espíritu, su humildad, sus grandes virtudes, su inteligencia, su condición de revolucionario sin fin, siempre estarán entre todos nosotros. Siempre lo vimos, lo consideramos y lo veremos, como un paradigma de profesor y de revolucionario, que trasciende a la presente y las futuras generaciones de profesionales de la salud y por todo ello no podemos dejar de decirle iGracias Apolo por tu ejemplo! 